\title{
A New Method of Capacitor Allocation and Sizing in Distribution Network Using Combined Fuzzy - Qv Analysis
}

\author{
Y. Gallal ${ }^{1}$, A. Fahmy ${ }^{2}$, W. M. Fayek ${ }^{2}$ And M. Ismail $^{3}$
}

\begin{abstract}
This paper presents a new approach for capacitor allocation and sizing in the modified IEEE 16 bus distribution system connected with wind machine with an objective of improving the voltage profile and reduction of power loss. Three cases are made with change the position of wind machine along three feeders in the proposed network, the case that gives better result for average bus voltage and total power losses selected for further simulation. The location of the buses where the capacitors should be placed is decided by a set of rules given by the Fuzzy Set Theory "FST" and the sizing of the capacitors determined by Q-V analysis in these buses. In addition calculated wind power factor "WPF" which achieve the reactive power required from wind farm in point of network connection "POC". A comparison is made between the proposed Fuzzy approach and the Particle Swarm Optimization "PSO" algorithm in terms of improves voltages with reduces losses achieved to study the performance of both Techniques.
\end{abstract}

Keywords: Fuzzy, PSO, distribution systems, capacitive compensation, loss minimization, wind generation.

\section{Introduction}

The loss minimization in distribution systems and improving the voltage profile has assumed greater significance recently since the trend towards distribution automation will require the most efficient operating scenario especially with integrated a renewable resources as wind generation machine which has economic benefits and reactive capability supporting distribution system voltage. Studies have indicated that as much as $13 \%$ of total power generated is wasted in the form of losses at the distribution level [1] thus use of Artificial Intelligent "AI" techniques for adapting with the network changes becomes more important. The influence of reactive power characteristics of loads is more apparent in a QV relationship. It shows the sensitivity and variation of bus voltages with respect to reactive power injections or absorptions [2]. An increase in Q will result an increase in voltage during normal operating conditions. Hence, Q-V analysis is used for sizing shunt capacitors in critical busses. The advantages with the addition of shunt capacitors banks are to improve the power factor, feeder voltage profile, Power loss reduction and increases available capacity of feeders. Therefore it is important to find optimal location and sizes of capacitors in the system to achieve the above mentioned objectives.

Since, the optimal capacitor placement and sizing is a complicated combinatorial optimization problem, many different optimization techniques and algorithms have been proposed in the past. Authors In [3] provides an evaluation of the practicality and accuracy of the capacitor placement algorithms including fuzzy set theory "FST" used in [4] to solve capacitor allocation problem contribute to better accuracy and practical in the results for consideration of physical node location and discrete capacitor sizes in radial feeders using load flow.

In this paper, novel method of capacitor allocation and sizing using combined Fuzzy-QV analysis are presented. Fuzzy to identify the suitable locations for capacitor placement then Q-V analysis is used for sizing shunt capacitors in critical busses which selected by fuzzy by apply a fictitious synchronous condenser at these busses.

Authors in $[5,6]$ determined candidate nodes by first identifying the branch in the system with the largest losses due to reactive currents. Then the node which contributes the largest load affecting the losses in that branch is selected as the candidate node.

Authors provide in $[7,8]$, a set of fuzzy rules has been used to determine suitable capacitor locations in a distribution system, the power loss reduction indices along with the p.u. nodal voltages are the inputs to the Fuzzy Inference System "FIS", which determines the node more suitable for capacitor installation, in [7] the author used the Plant Growth Simulation combined with fuzzy for capacitor sizing but in [8] the author used the HPSO combined with fuzzy for capacitor sizing.

In proposed fuzzy model, the power loss reduction indices along with the p.u. nodal voltages are the inputs to the Fuzzy Inference System "FIS", which determines the node more suitable for capacitor installation then apply QV analysis on selected buses for capacitor sizing.

\footnotetext{
${ }^{1}$ Prof. Electrical and Control Eng. Dept. Arab Academy for Science and Technology and Maritime Transport.

${ }^{2}$ Electrical and Control Eng. Dept. Helwan University.

${ }^{3}$ Eng., Research and Studies Sector, Egyptian Electricity Transmission Company, Cairo Egypt Eng_mahismael@yahoo.com. Tel. 00201008172174
} 
The modeling of WTG for load flow analysis is necessary to study connection requirements which include reactive capability of wind farm. This approach is achieved by connecting wind farm to the proposed network, Type 3 - doubly-fed asynchronous generators WTGs has capability to generate max output active power at WPF reference equal " 1 " at POC this mean no reactive power generated by the wind farm. Additional reactive power support equipment required in the wind farm to generate sufficient MVAR in certain WPF in order to support voltage stability in proposed network, new WPF which achieve reactive power requirement at POC will be calculated.

The paper is organized as follow: First, in Section II, an overview of the problem formulation, the IEEE modified system under study is presented and the power flow algorithm used for simulation, In Section III, Frame of the approach including fuzzy set theory "FST" Implementation, capacitor sizing by QV analysis and calculation reactive power requirement for wind farm connection. Simulation results are given in Section IV, for exhibiting the FST technique performance and its effectiveness compared to the PSO and the base case "before using fuzzy". Simulation results are given in Section IV. Finally, conclusions are drawn in Section V.

\section{Problem Formulation}

The capacitor placement problem is the determination of the location, number and sizes of the shunt capacitors to be placed on a radial distribution system. The power losses consumed as $\mathrm{I}^{2} \mathrm{R}$ at the distribution level. Reactive currents account for a portion of these losses. By the installation of shunt capacitors, the losses produced by reactive currents can be reduced. Hence, it is essential to find the optimal location and size of capacitors required to maintain good voltage profile and to reduce feeder losses.

\subsection{System Under Study}

This modified IEEE network consists of 16 buses, three feeder distribution system [9] base 100MVA, and $23 \mathrm{KV}$ as shown in Fig. 1. the three-phase system is considered as balanced and loads are assumed as time invariant.

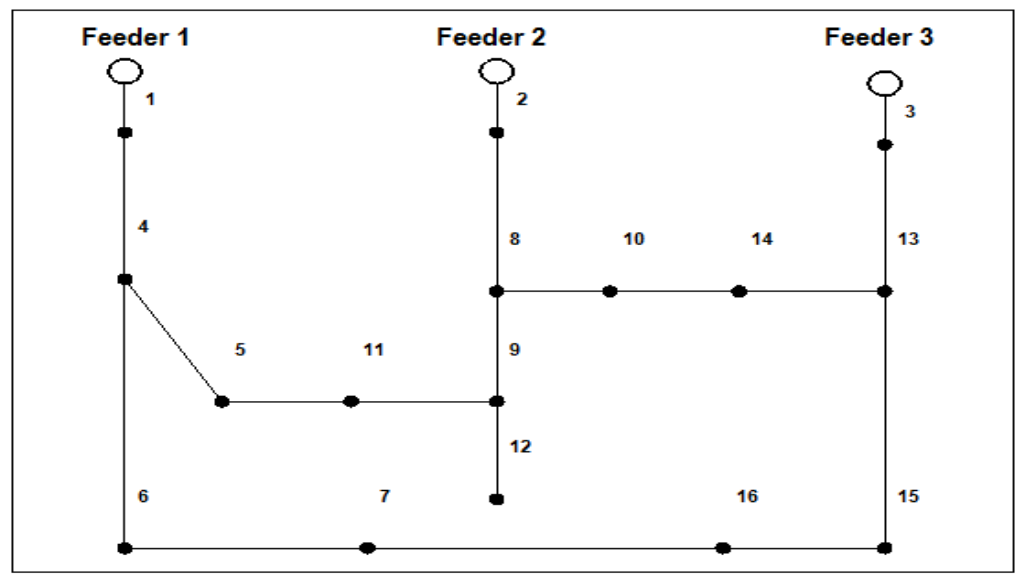

Fig. 1. Modified IEEE 16 bus, three feeder system.

Table 1 shows the line data. Using MATLAB program, Bus data and Line data are given as inputs to the load flow program by Gauss-Seidel method. After power flow solution power loss and voltage of each bus are inputs to FST.

Table 1. Three feeder system data "base $100 \mathrm{MVA}, 23 \mathrm{kv}$ "

\begin{tabular}{|c|c|c|c|c|}
\hline $\begin{array}{c}\text { Line } \\
\text { From-To }\end{array}$ & $\begin{array}{c}\text { Resistance } \\
\text { "p.u." }\end{array}$ & $\begin{array}{c}\text { Reactance } \\
\text { "p.u." }\end{array}$ & $\begin{array}{c}\text { P(MW) } \\
\text { "End bus" }\end{array}$ & $\begin{array}{c}\text { Q(MVAR) } \\
\text { "End bus" }\end{array}$ \\
\hline $1-4$ & 0.075 & 0.10 & 7.50 & 6.0 \\
\hline $4-5$ & 0.080 & 0.11 & 12.00 & 6.0 \\
\hline $4-6$ & 0.090 & 0.18 & 15.00 & 5.0 \\
\hline $6-7$ & 0.040 & 0.04 & 6.25 & 8.1 \\
\hline $2-8$ & 0.110 & 0.11 & 12.00 & 6.0 \\
\hline $8-9$ & 0.080 & 0.11 & 10.50 & 4.0 \\
\hline $8-10$ & 0.110 & 0.11 & 4.44 & 5.0 \\
\hline $9-11$ & 0.110 & 0.11 & 3.00 & 4.0 \\
\hline $9-12$ & 0.080 & 0.11 & 12.00 & 4.0 \\
\hline $3-13$ & 0.110 & 0.11 & 4.44 & 4.0 \\
\hline $13-14$ & 0.090 & 0.12 & 5.70 & 4.0 \\
\hline
\end{tabular}




\begin{tabular}{|c|c|c|c|c|}
\hline $15-16$ & 0.040 & 0.04 & 10.00 & 5.0 \\
\hline $10-14$ & 0.040 & 0.04 & - & - \\
\hline $5-11$ & 0.040 & 0.04 & - & - \\
\hline
\end{tabular}

\subsection{Load Flow Solution by G-S Method}

Use Gauss-Seidel Method because the physics of the problem are understood, a close initial guess can be made and decreasing the number of iterations needed. Reference [10] presents Hadi Saadat load flow program by Gauss-Seidel method.

Wind machine locate at feeder 1 , feeder 2 and feeder 3 at cases 1, 2 and 3 respectively and conventional machines in other feeders in network shown in Fig. 2. Bus data and Line data are given as inputs to the load flow program by Gauss-Seidel method; this gives power loss and voltage of each of the bus in different cases. After comparing between three cases as shown in Fig. 2 and Table 2 appear that case 3 gives better average bus voltage equal 0.9 p.u and minimum total active power losses equal 10.22 MW which is used for further analysis.

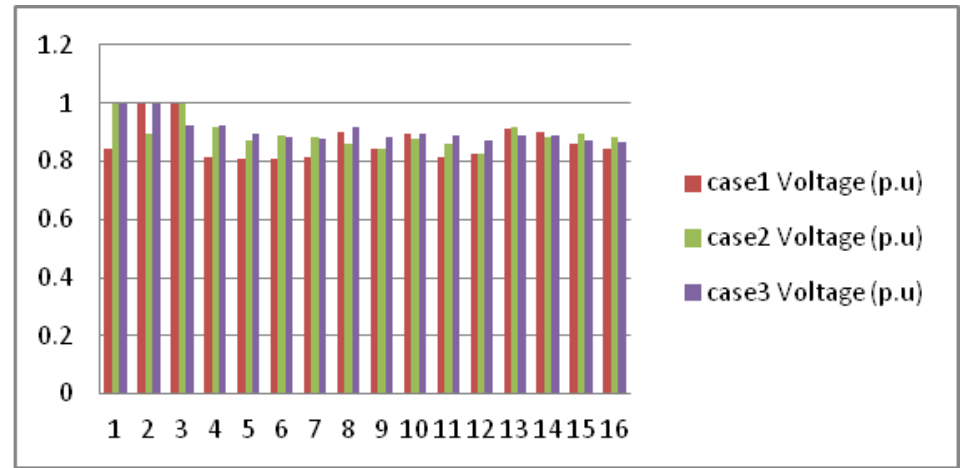

Fig. 2. Node Voltage comparing between cases 1, 2, 3 .

Table 2. Total P loss "MW" \& Average Bus Voltage "p.u".

\begin{tabular}{|c|c|c|c|}
\hline Before Capacitor Placement & Case1 & Case2 & Case3 \\
\hline Total active Power Loss (MW) & 13.39 & 11 & 10.22 \\
\hline Average bus voltage (pu) & 0.868313 & 0.894313 & 0.90459 \\
\hline
\end{tabular}

\section{Framework Of The Approach}

The entire framework of this approach to solve the optimal capacitor allocation and sizing problem using combined Fuzzy-QV analysis as shown in Fig. 3.

1. First load flow solution for the original system is required to obtain the active power losses and buses voltage in the system for three different wind machine locations between three feeders.

2. After comparing results from load flow solution between three cases in term of total power loss and average bus voltage, the better case is chosen for further analysis.

3. Proposed fuzzy model, load flow solutions again are required to obtain the power loss reduction by compensating the total reactive load at every node of the distribution system. The loss reductions are then, linearly normalized into a " 0,1 " range with the largest loss reduction having a value of 1 and the smallest one having a value of 0 . These power loss reduction indices along with the per unit node voltages are the inputs into the FST, which determines the most suitable node for capacitor installation by fuzzy inference system.

4. Q-V analysis is then used to determine the optimal size of capacitor to be placed at the chosen node from each fuzzy model in previous point 3.

5. Comparing result for capacitor allocation and sizing between the proposed fuzzy-QV analysis and PSO models in term of better result in total power loss and average bus voltage with minimum capacitors rating.

6. The new wind power factor calculated at which wind machine generate sufficient reactive power to support network voltage, this new WPF help planning engineer to establish wind grid code and design the wind machine to be able to achieve this requirement.

\subsection{Fuzzy Set Theory (FST) Implementation}

The proposed fuzzy model as in reference [7] author Provides in section III detailed identification of optimal capacitor locations using fuzzy approach, a set of fuzzy rules has been used to determine suitable capacitor locations in a distribution system. In the first step, load flow solution for the original system is required to obtain the active power losses in the system. Again, load flow solutions are required to obtain the 
power loss reduction by compensating the total reactive load at every node of the distribution system. The loss reductions are then, linearly normalized into a " 0,1 " range with the largest loss reduction having a value of 1 and the smallest one having a value of 0 . Power Loss Index value for nth node can be obtained using Eq. (1).

Where LR is Loss Reduction

$$
P L I_{n}=\frac{L R_{(n)}-L R_{(\min )}}{L R_{(\max )}-L R_{(\min )}}
$$

These power loss reduction indices along with the p.u. nodal voltages range varies from 0.9 to 1.1 are the inputs to the Fuzzy Inference System "FIS" and output variable is capacitor suitability index. This fuzzy model containing a set of rules is then used to determine the capacitor placement suitability of each node in the distribution system. Capacitors can be placed on the nodes with the highest suitability.

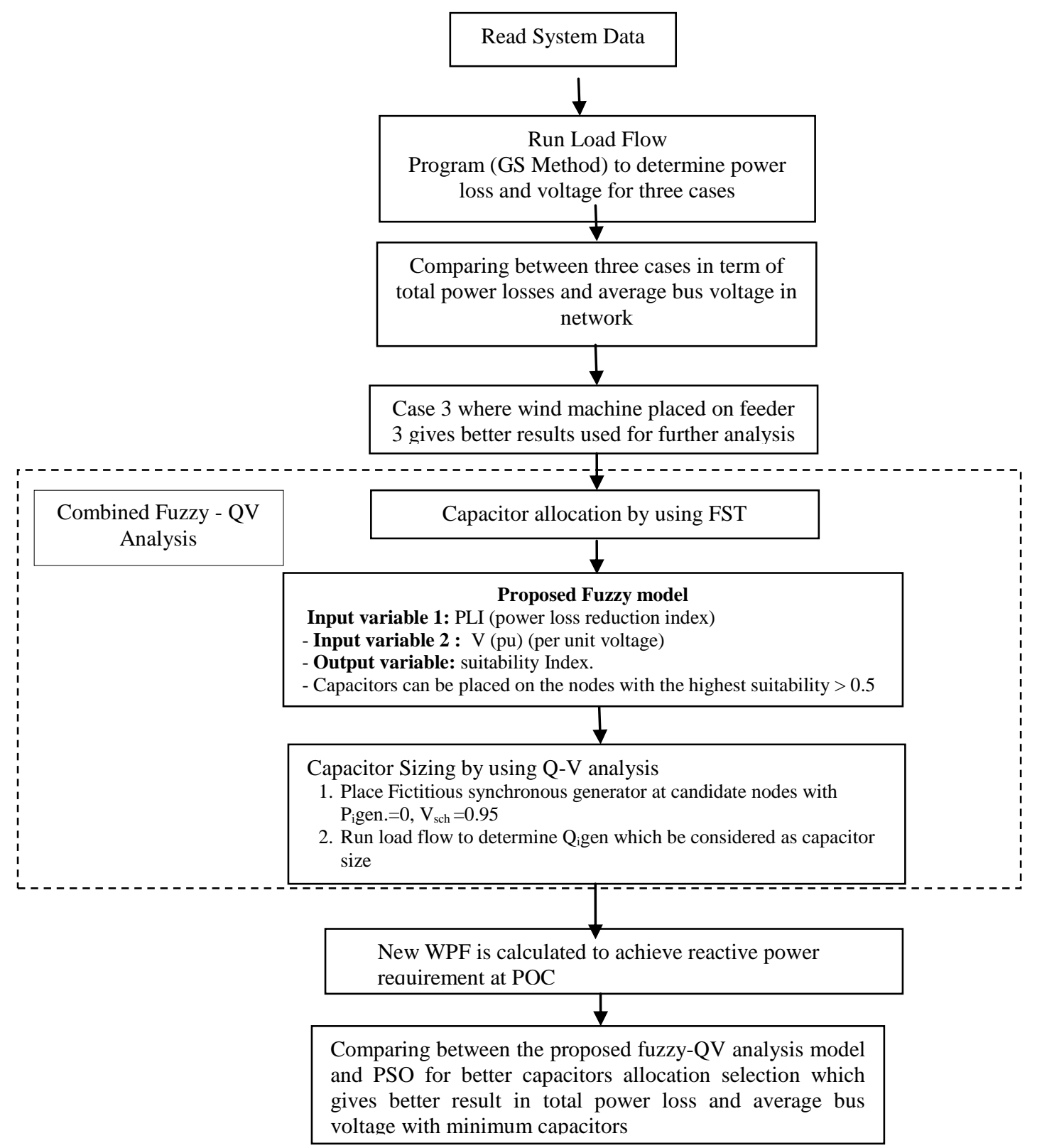

Fig. 3. Flow Diagram of the Proposed Approach.

The Membership Function Editor is used to define the shapes of all the membership functions associated with each variable. In this present work, five membership functions are selected for power loss index. They are L, LM, M, HM and H. All the five membership functions are triangular as shown in Fig. 4. Five membership functions are selected for Voltage. They are L, LN, N, HN and H. These membership functions are 
trapezoidal and triangular as shown in Fig. 5. Five membership functions are selected for suitability Index. They are $\mathrm{L}, \mathrm{LM}, \mathrm{M}, \mathrm{HM}$ and $\mathrm{H}$. These five membership functions are also triangular as shown in Fig. 6.

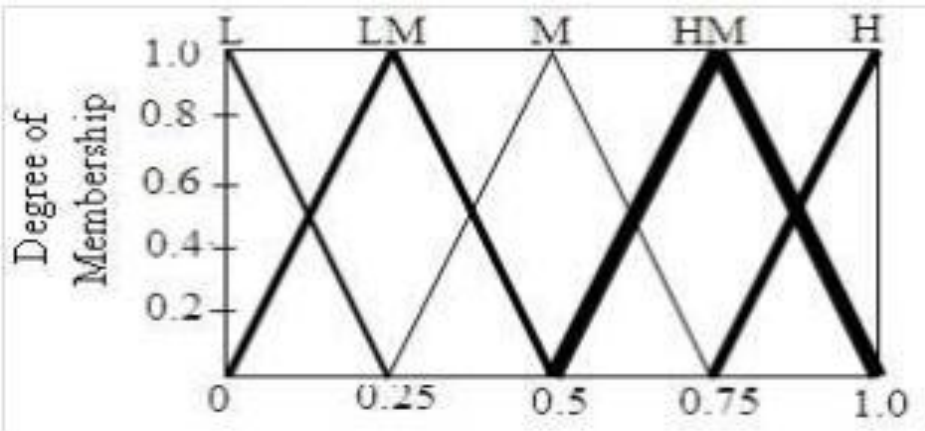

Fig. 4. Membership Function for Power Loss Index or node branches loss.

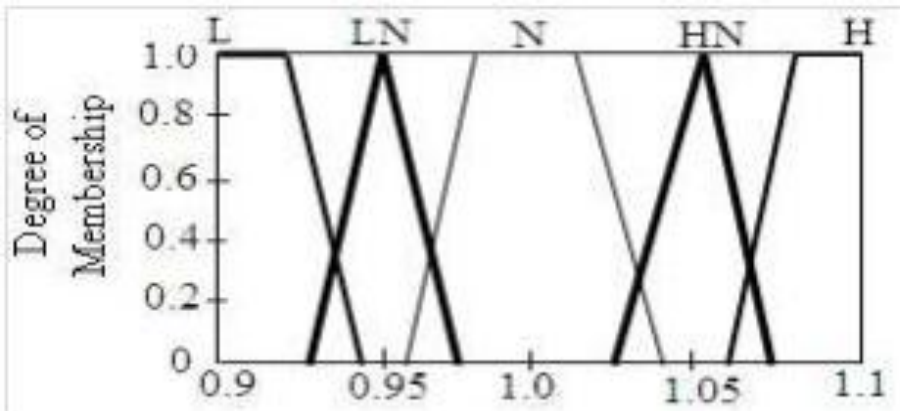

Fig. 5. Membership Function for Bus Voltage.

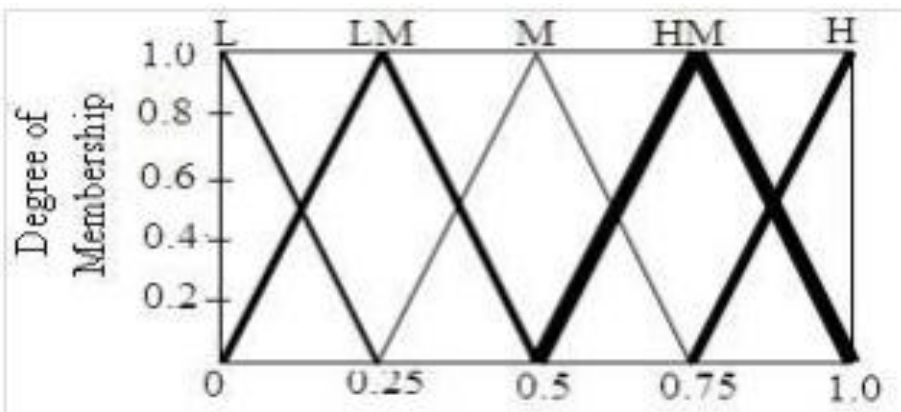

Fig. 6. Membership Function for suitability Index.

For determining the suitability of capacitor placement at a particular node, a set of multiple-antecedent fuzzy rules has been established. The inputs to the rules are the voltage and power loss and the output is the suitability of capacitor placement. The rules are summarized in the fuzzy decision matrix in Table 3 . In the present work 25 rules are constructed.

For Example:

If PLI is $\mathrm{H}$ and Voltage is $\mathrm{L}$ then suitability Index is $\mathrm{H}$

If PLI is M and Voltage is $\mathrm{N}$ then suitability Index is LM

If PLI is $\mathrm{H}$ and Voltage is $\mathrm{H}$ then suitability Index is LM

Table 3. Fuzzy Decision Matrix for Capacitor Location.

\begin{tabular}{|c|c|c|c|c|c|c|}
\hline \multirow{2}{*}{\multicolumn{2}{|c|}{ AND }} & \multicolumn{5}{|c|}{ Voltage } \\
\hline & & $L$ & $L N$ & $N$ & $H N$ & $H$ \\
\hline \multirow{5}{*}{$\begin{array}{l}\text { Power Loss Index } \\
\text { (PLI) }\end{array}$} & $L$ & L M & L M & $\mathrm{L}$ & $\mathrm{L}$ & $\mathrm{L}$ \\
\hline & $L M$ & $\mathrm{M}$ & L M & L M & $\mathrm{L}$ & $\mathrm{L}$ \\
\hline & $M$ & $\mathrm{H} \mathrm{M}$ & $M$ & L M & $\mathrm{L}$ & $\mathrm{L}$ \\
\hline & $H M$ & $\mathrm{HM}$ & $\mathrm{H} \mathrm{M}$ & $\mathrm{M}$ & L M & $\mathrm{L}$ \\
\hline & $H$ & $\mathrm{H}$ & $\mathrm{H} \mathrm{M}$ & $\mathrm{M}$ & LM & LM \\
\hline
\end{tabular}


The suitability Index values corresponding to each bus can be obtained the higher value of suitability Index for a bus gives more probability of capacitor allocation at the same bus. Thereby, we can find the nodes suitable for capacitor installation. The sizing of capacitors at buses done by using QV analysis.

\subsection{Capacitor Sizing by QV Analysis}

The $\mathrm{Q}-\mathrm{V}$ curve method uses a fictitious synchronous condenser "a synchronous generator with Pgen = 0 and wide limits of reactive power" at the bus where the Q-V curves are to be generated. Q-V curves are generated at any bus by setting a desired bus voltage magnitude and solving the power flow to the desired voltage value. The amount of reactive power generated by the condenser at the bus is the required reactive power to hold the voltage at the desired value. This process is repeated for a range of voltages and a $\mathrm{Q}-\mathrm{V}$ curve at the bus can be plotted.

Figure 7 shows an example of Q-V curve plot. The curve is plotted for a specific system load. The load bus reaches the " 0 " Mvar point where the magnitude of the receiving end voltage "V2" is approximately 1.02 p.u.

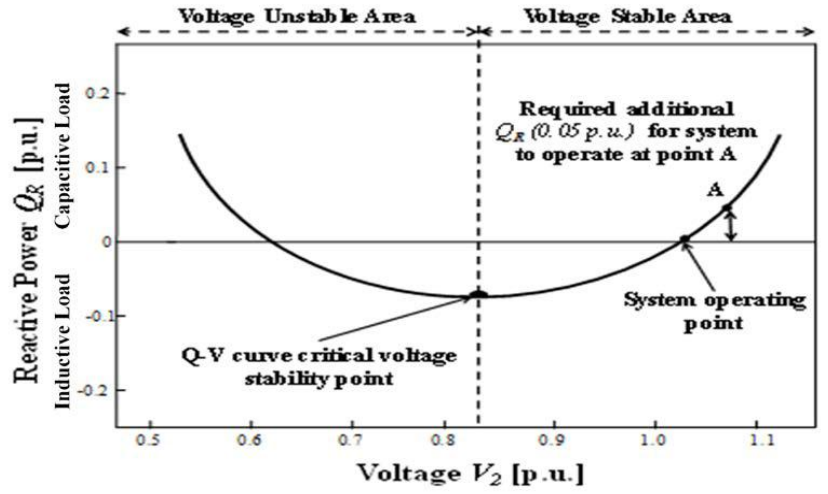

Fig. 7. Q-V Curve Method.

Fictitious synchronous generator at target bus "I" generate active power " $\mathrm{P}_{\mathrm{i}} \mathrm{gen}$ " equal zero at machine schedule voltage 0.95 p.u. as a minimum permissible bus voltage limit and the limits of generated reactive power is expressed as: $0 \leq \mathrm{Q}_{\mathrm{i}}$ gen. $\leq 40$.

After load flow solution again with applies fictitious generators at buses which selected by fuzzy at the same time, target buses absorb reactive power from fictitious generators until bus voltage reach machine schedule voltage predefined. Every Fictitious synchronous generator at any bus affected voltage in neighboring buses also thus we make QV analysis to all buses which need compensation at the same time so the minimum reactive power needed can determined which achieve target objective.

\subsection{The Reactive Power Requirement For Wind Farm Connection}

For bulk system studies, it is impractical and unnecessary to model the collector system network inside the plant to the level of detail .The single-machine equivalent is the recommended approach to represent wind power plants "WPPs" in Western Electricity Coordinating Council "WECC" base cases [11].

A first version of the WECC generic models has been implemented in several simulation platforms being used in WECC, including the General Electric PSLF and Siemens PTI "PSS/E" simulation platforms. Although there are differences in the program implementation, the models are functionally equivalent and have the same set of parameters.

In this model represent WTG with capacity 30 MW (6WTGsX5MW) Type 3 - doubly-fed asynchronous generators WTGs has capability to generate max output active power equal 30MW at WPF reference equal " 1 " at POC this mean no reactive power generated by the wind farm, the control mode is specified by setting the VAR parameter as power factor control and the power factor reference is set by the initial load flow condition "Qgen_init/ Pgen_init" in "POC" as unity power factor.

\subsection{PSO}

\section{Simulation Study}

In this section, PSO algorithm is proposed for the optimization of the case 3 study, the objective function includes the voltage and capacitor constraints for capacitor allocation implementation in the pre specified network 
- Voltage constraint: Eq.(2):

The voltage magnitude at each bus must be maintained within a specified limit expressed as follow in

$$
V_{\min } \leq\left|V_{i}\right| \leq V_{\max } \quad i: 1,2,3, \ldots ., n
$$

where $V_{i}$ is the voltage magnitude of the bus $i, V_{\min }$ and $V_{\max }$ are bus minimum and maximum voltage limits respectively.

- Constraints of capacitor placement:

The distribution of different capacitor bank locations and ratings depend upon the network configuration and actual load values, the capacitor sizes and location are placed on those circuits with heavy MVAR load.

Finally the fitness function can be described as follows Eqs. $(3,4)$ :

$$
\text { Min } F=\min (\text { constrains) }
$$

Where:

$$
\text { Constrains }=P_{\text {loss }}+R_{\text {cap }}+V_{\text {pen }}
$$

$P_{\text {loss }}$ is the total power loss.

- $\quad R_{\text {cap }}$ is the capacitor rating

- $\quad$ Vpen is the Voltage constraints penalty.

And considering the WPF as calculated in Proposed Technique using FST with Q-V analysis in case3 equal "0.99". The result shown in comparing tables and figures with Fuzzy-QV analysis in the next section 4.2.

\subsection{Combined Fuzzy- QV Analysis Method}

The simulation has been done using MATLAB M-FILE program. The effectiveness of the proposed method for loss reduction and voltage improvement by capacitor placement is tested on case 3 of network configuration as shown in Fig. 8 in which wind machine placed on feeder 3 . The results obtained in these methods are explained in the following sections.

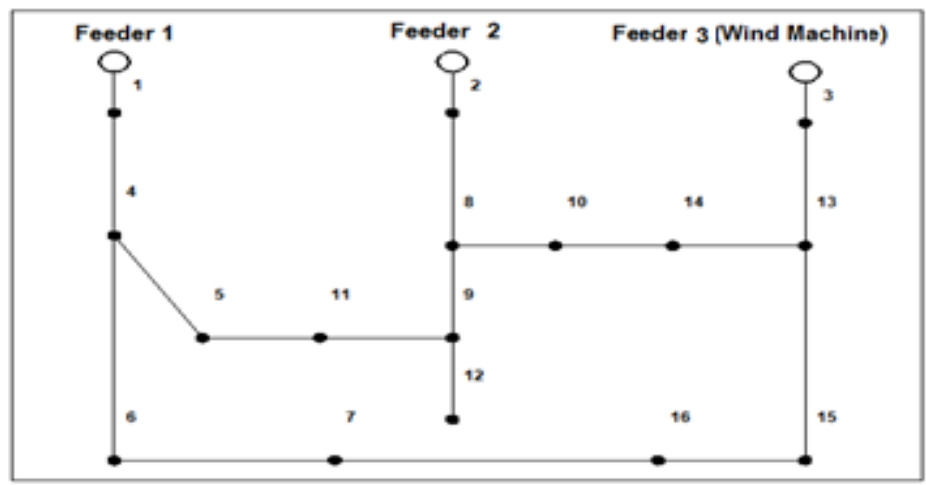

Fig. 8. Cases3 network configuration.

Figure 9 the sensitivity values for all buses as output from the fuzzy model. The higher value of suitability Index for a bus gives more probability of capacitor allocation at the same bus. The buses are ordered according to their sensitivity value have the highest Candidate suitability Index of greater than 0.5 are selected as optimal candidate locations.

From the output from fuzzy model, the candidate buses number are " $5,6,7,9,10,11,12,14,15$ and 16 " which will make QV analysis on it for capacitor sizing.

The comparison between proposed method and PSO for capacitor sizing shown in Table 4 and the generated reactive power from three machines when capacitors inserted shown in Table 5 and the voltage of each of the bus after compensation shown in Fig. 10. The initial power loss and it is reduction after capacitor placement shown in Table 6. 


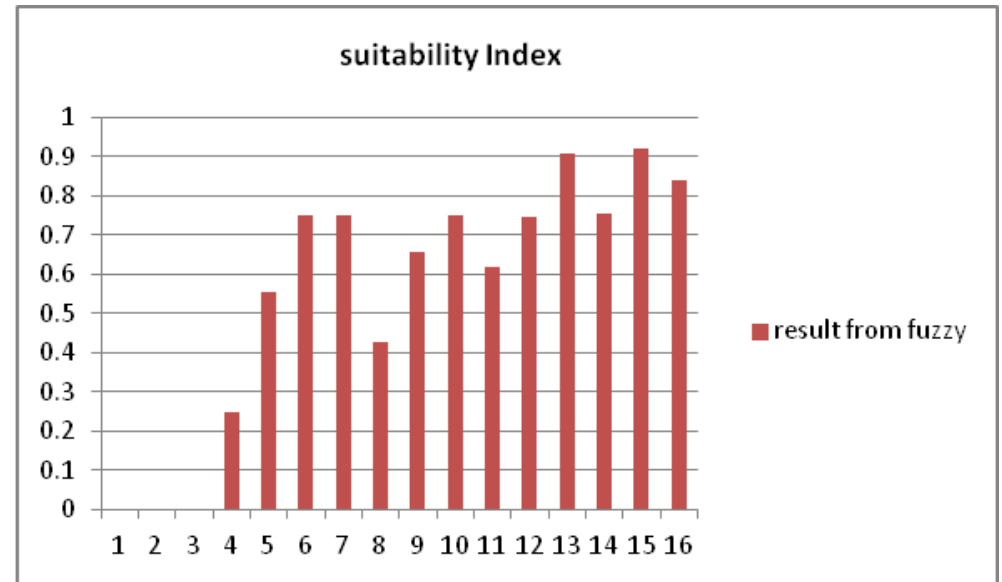

Fig. 9. Suitability Index.

Table 4. Results of Capacitor Sizing.

\begin{tabular}{|c|c|c|}
\hline Bus no. & $\begin{array}{c}\text { Fuzzy } \\
\text { Qcap (MVAR) }\end{array}$ & $\begin{array}{c}\text { PSO } \\
\text { Qcap (MVAR) }\end{array}$ \\
\hline 5 & 1.7 & 11.4 \\
\hline 6 & 3.89 & 5.11 \\
\hline 7 & 9.51 & 15 \\
\hline 8 & - & 9 \\
\hline 9 & 8.98 & - \\
\hline 10 & 2 & - \\
\hline 11 & 7.4 & -2 \\
\hline 12 & 12.82 & - \\
\hline 13 & - & 13 \\
\hline 14 & 6.98 & - \\
\hline 15 & 3.35 & 66 \\
\hline 16 & 15.03 & \\
\hline
\end{tabular}

Table 5. Q "MVAR" generated by CONVENTIONAL MACHINE.

\begin{tabular}{|c|c|c|}
\hline Bus No & Fuzzy Qgen. "MVAR" & $\begin{array}{c}\text { PSO Qgen. } \\
\text { "MVAR" }\end{array}$ \\
\hline 1 & -0.62 & 3.5 \\
\hline 2 & -3.22 & -1.4 \\
\hline $\begin{array}{c}3 \\
\text { wind machine }\end{array}$ & 4.198 & 4.27 \\
\hline Total MVAR & 0 & 6.3 \\
\hline
\end{tabular}

Table 6. Total P loss "MW" \& Average Bus Voltage "p.u”.

\begin{tabular}{|l|c|c|c|}
\hline \multicolumn{1}{|c|}{ After Capacitor Placement } & Base Case & $\begin{array}{c}\text { Fuzzy model combined with QV } \\
\text { analysis }\end{array}$ & PSO \\
\hline Total active Power Loss (MW) & 10.22 & 5.96 & 5.88 \\
\hline Average bus voltage (pu) & 0.90459 & 0.976 & 0.96 \\
\hline
\end{tabular}

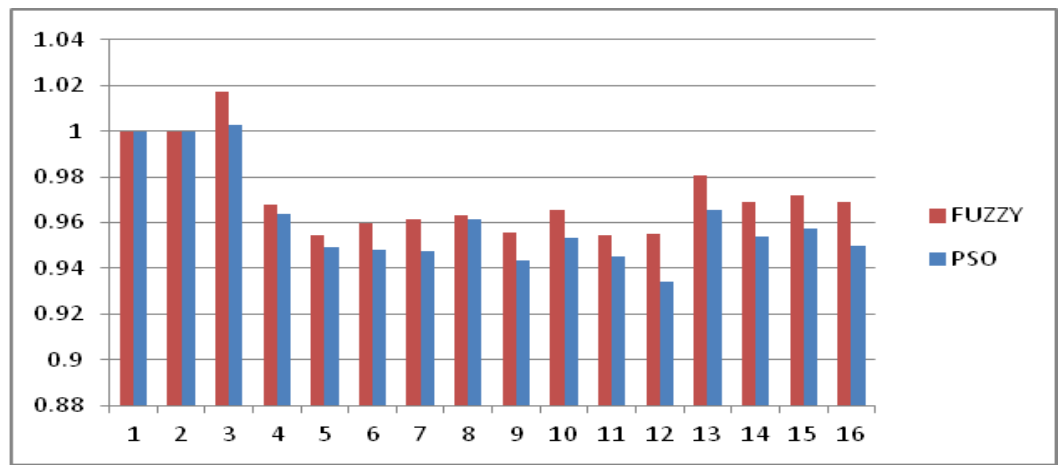

Fig. 10. Node Voltage after compensation. 
New WPF is calculated to achieve reactive power requirement at POC, QV analysis done in wind machine bus by set schedule voltage of fictitious synchronous machine 1p.u. and set its active power generated equal wind generated power $30 \mathrm{MW}$, after power flow solution the generated reactive power is the target reactive requirement from wind farm then the new WPF is achieved which indicate to the required reactive compensation needed internal in WPP.

As the result using fuzzy model combined with QV analysis the new WPF is 0.99 at which wind machine can generate reactive power equal 4.19 MVAR at active power generated equal 30MW.

Finally, the voltage profile enhancement when using Fuzzy or PSO techniques is depicted compared with the base case.

\section{Conclusions}

A new and efficient approach that employs fuzzy combined with Q-V analysis technique for capacitor placement and sizing in the IEEE 16 bus distribution network connected with wind machine. After select the better location for wind machine between three feeders. The FST is used to determine the optimal locations of the buses required for compensation, fuzzy rules has been established. The inputs to the rules are the "voltage" and "node branches loss" and the output is the suitability of capacitor placement. The Q-V analysis is used to size the required level of shunt capacitive compensation at the optimal candidate locations. The simulation result appear improving in the voltage profile of the system and reduce the power loss and calculate new WPF which achieve reactive power requirement to support its bus voltage at POC. The result comparing with PSO algorithm in term of total active power loss and average bus voltage in the network after using capacitor allocation and sizing.

\section{References}

[1]. Song, Y. H., Wang, G. S., Johns, A. T., and Wang, P. Y., "Distribution Network Reconfiguration for Loss Reduction using Fuzzy Controlled Evolutionary Programming”, IEE Proc. Gener. Transm. Distrib., Vol. 144, No. 4, pp.345-350, 1997.

[2]. Kundur, P., "Power System Stability and Control", McGraw-Hill Inc., New York, USA, 1994.

[3]. Ng, H.N., Salama, M.M.A. and Chikhani, A.Y., Classification of capacitor allocation techniques, IEEE Trans. On Power Delivery, Vol. 15, No. 1, pp.387-392, 2000.

[4]. Ng, H.N., Salama, M.M.A. and Chikhani, A.Y., Capacitor allocation by approximate reasoning: fuzzy capacitor placement, IEEE Trans. on Power Delivery, Vol. 15, No. 1, pp.393-398, 2000.

[5]. Abdel-Salam, T.S., Chikhani, A.Y., and Hackam, R., "A New Technique for Loss Reduction Using Compensating Capacitors Applied to Distribution Systems With Varying Load Condition”, IEEE T-PWRD, Vol. 9, NO. 2, pp. 819-827, 1994.

[6]. Ng, H.N., Salama, M.M.A., and Chikhani, A.Y., "Capacitor placement in distribution systems using fuzzy technique", 1996 Canadian Conference on Electrical and Computer Engineering, Calgary, Alberta, pp. 790-793, 1996.

[7]. S.M. Kannan1*, P. Renuga2, A. Rathina Grace Monica1 "Optimal capacitor placement and sizing using combined fuzzy-HPSO method" International Journal of Engineering, Science and Technology Vol. 2, No. 6, pp. 75-84, 2010.

[8]. R. Srinivasa Rao 'Optimal Capacitor Allocation for loss reduction in Distribution System Using Fuzzy and Plant Growth Simulation Algorithm', International Journal of Electrical and Computer Engineering 5:2 2010.

[9]. Whei - Min Lin Hong - Chan Chin "A New Approach for Distribution Feeder Reconfiguration for Loss Reduction and Service Restoration” IEEE Transactions on Power Delivery, Vol. 13, No. 3, 1998.

[10]. Power flow solution by Gauss-Seidel method Copyright (c) by H. Saadat, 1998.

[11]. WECC Renewable Energy Modeling Task Force "WECC Wind Power Plant Dynamic Modeling Guide", Western Electricity Coordinating Council Modeling and Validation Work Group. 